\title{
PESQUISADORES DE INFORMAÇÃO EM SAÚDE E COMPETÊNCIA INFORMACIONAL: RELATO DE EXPERIÊNCIA
}

\author{
Valdinéa Sonia Petinari \\ Vanda de Fátima Fulgêncio de Oliveira \\ Rosana Evangelista \\ Sandra Lúcia Pereira
}

\section{Resumo:}

Objetivo: Relatar uma experiência de atuação em Unidade Informacional inserida em um Hospital Universitário, que visa disponibilizar informações, em quaisquer suportes, com foco centrado nas necessidades informacionais voltada para os profissionais da área de saúde. Resultado: Existe uma demanda de acesso rápido a informação e orientação dos profissionais da área de saúde por profissionais da área de informação. Conclusão: Ao relatar esta experiência de atuação em uma Unidade Informacional inserida em Hospital Universitário, pode-se entender que a sua existência propicia o rápido acesso a informação e que há demanda.

\section{Palavras-chave:}

Competência informacional; Profissional da informação; Bibliotecas e unidades de informação em saúde

\section{HEALTH INFORMATION RESEARCHERS AND INFORMATION LITERACY: EXPERIENCE REPORT}

\begin{abstract}
:
Objective: Report of experience in Informational Unit within an University Hospital, which aims to provide information, in any kind of media, focusing on the specific necessities of health professionals. Findings: There is a demand for fast access to information and for guiding health's professionals on the part of information professionals. Conclusion: On reporting the experience at this Informational Health, established in an University Hospital, it is possible to say that its existence propitiates the quick access to information and that this demand is real.
\end{abstract}

\section{Keywords:}

Information literacy; Information’s professional; Health libraries; Health information units 


\section{Introdução}

Os profissionais da informação, que atuam na área da saúde, necessitam de qualificação, especialização, aperfeiçoamento e um aprendizado permanente. Sabe-se que as pesquisas para fins acadêmicos e para tomada de decisões clínicas e de gestão apresentam-se de forma entrelaçada na prática dos pesquisadores da área da saúde.

As informações demandadas para a pesquisa em saúde e para a tomada de decisões clínicas e de gestão podem ser divididas em duas formas: a informação científica que deve ser metodologicamente estruturada e a informação para a gestão em saúde, não sendo necessariamente científica, também fundamental para o processo decisório (PINTO, 2005).A atuação do profissional da informação na área da saúde expande-se para dar suporte aos profissionais da área, na medida em que são utilizadas novas ferramentas de pesquisa. Percebe-se que estes profissionais têm uma tendência a assumir cada vez mais responsabilidades junto ao processo de tomada de decisão (BLATT, 2001; BUENO; BLATTMANN, 2005; SILVA, 2005), o que significa que, uma demanda por informação em saúde exige, diretamente, que o profissional da informação aplique sua competência para atender esta demanda recorrendo a sua capacitação e seu conhecimento dos meios para se chegar à informação adequada e responder a demanda sem deixar dúvidas de confiabilidade (EVANGELISTA et al, 2008).

Para Le Coadic (2004) é preciso que conheçamos as circunstâncias que levam o usuário a iniciar um processo de busca de informações, se quisermos compreender os fenômenos que ocorrerão quando do uso dos distintos sistemas, serviços e produtos mobilizados pelo usuário. A consulta que o usuário formulará ao sistema, a interação que ocorrerá entre o usuário e o sistema (ou o intermediário) e a avaliação do êxito ou prejuízo dessa interação dependerão destas circunstâncias.

Na prática, a análise das necessidades é uma atividade interativa que alterna coleta de dados (coleta direta e/ou indireta por meio de medições e levantamentos), análise desses dados e decisão (LE COADIC, 2004). 


\section{ARTIGO}

Faria et al (2005) apontam as competências requeridas aos profissionais da informação na sociedade atual, das quais destacam-se aqui: conhecimento interdisciplinar e especializado; capacidade de contextualização; capacidade de conceituação; conhecimento da demanda ou do cliente; domínio de tecnologias de informação; adaptação ao novo, flexibilidade e abertura às mudanças.

Outra competência fundamental hoje para os pesquisadores e profissionais da informação é a chamada Competência Informacional/Information Literacy que pode ser definida como:

o processo contínuo de internalização de fundamentos conceituais, atitudinais e de habilidades necessário a compreensão e interação permanente com o universo informacional e sua dinâmica, de modo a proporcionar um aprendizado ao longo da vida (DUDZIAK, 2003, p. 28).

A Association of College \& Research Libraries (ACRL), divisão da American Library Association, organizou um documento que define e fornece as aplicações de Information Literacy. Para esta instituição, Information Literacy fornece habilidades aos indivíduos que os tornam capazes de reconhecer quando uma informação é necessária de forma que saibam localizar, avaliar e usar efetivamente a informação.

Ainda de acordo com a American Library Association (ASSOCIATION, 2000) estas habilidades são cada vez mais exigidas, uma vez que proliferam mudanças nos recursos tecnológicos para a recuperação do grande volume de informação atualmente disponível. É comum a todas as disciplinas, a todos os ambientes de aprendizagem e a todos os níveis de instrução a abundância de informação, entretanto, sem um conjunto de habilidades necessárias, o seu uso torna-se pouco eficaz. Para tanto, é fornecido no documento da ACRL, um conjunto de normas, indicadores de desempenho e resultados que podem ser aplicados na diversidade de áreas sugeridas.

Cavalcante (2006) comenta as discussões atuais relativas à competência informacional nas universidades, acentuando que a educação superior está relacionada principalmente com o uso das tecnologias, em diferentes suportes de informação, para favorecer o desenvolvimento das competências dos estudantes, o que beneficiará o crescimento 
profissional, a capacidade de realização de pesquisa, planejamento, gestão e avaliação no uso de fontes de informação.

Esta realidade se dá como reflexo das novas tecnologias de informação e comunicação agregadas nos últimos anos às fontes informacionais tradicionais usadas pelos pesquisadores, exigindo-se cada vez mais dos mesmos conhecimentos e informação qualificada, o que provoca simultaneamente uma demanda de mais serviços de informação e profissionais especializados em informação, tornando-se necessário que os pesquisadores, profissionais da saúde, busquem orientação de profissionais da informação para sua prática cotidiana profissional e acadêmica.

Neste contexto, propõe-se fazer um breve relato de atuação em uma unidade informacional especializada para atendimento das necessidades informacionais de profissionais da área da saúde.

A Unidade de Informação aqui apresentada, denominada Célula de Documentação Científica, está situada no interior de um Hospital Universitário e tem como objetivo disponibilizar informações, em quaisquer suportes, aos usuários do Hospital Universitário, com foco centrado em suas necessidades informacionais. As atividades estão estabelecidas e legitimadas pelo Núcleo Técnico de Gestão por Processos da Instituição. Importante salientar que essa Unidade de Informação é um dos vários serviços informacionais disponíveis dentro da universidade para a comunidade científica, a qual tem acesso a uma ampla e complexa rede de informações e recursos.

Estão discriminadas, no quadro abaixo, as tarefas realizadas pela Célula de Documentação Científica e os resultados esperados, quando estas são realizadas, onde são realizadas, por quem são realizadas e quais os procedimentos detalhados para a execução de cada tarefa.

(C) Revista Digital de Biblioteconomia e Ciência da Informação,Campinas, , v.7, n. 1, p. 180-189, jul./dez. 2009- ISSN: 1678-765X. 
ARTIGO

\section{Quadro Síntese da Gestão de Processos da Célula de Documentação Científica}

\begin{tabular}{|c|c|c|c|c|c|}
\hline O quê? & Resultado esperado & Quando & Onde & Quem & Procedimento \\
\hline $\begin{array}{l}\text { Tarefas: T-1 } \\
\text { Serviço de } \\
\text { Referência }\end{array}$ & $\begin{array}{l}\text { Prestar atendimento de pesquisa de } \\
\text { documentos em bases de dados } \\
\text { especializadas; possibilitar a } \\
\text { localização e obtenção de } \\
\text { documentos; orientar o usuário } \\
\text { nas buscas, na elaboração e } \\
\text { apresentação de trabalhos técnicos } \\
\text { científicos e disseminar } \\
\text { seletivamente as informações de } \\
\text { interesse potencial dos usuários }\end{array}$ & $\begin{array}{l}\text { De segunda } \\
\text { à } \\
\text { Sexta } \\
\text { Das } 8.30 \text { às } \\
17 \mathrm{~h}\end{array}$ & $\begin{array}{l}\text { Célula de } \\
\text { Documentação } \\
\text { Científica com } \\
\text { uso de } \\
\text { Computadores }\end{array}$ & $\begin{array}{c}\text { Bibliotecário } \\
\text { e } \\
\text { Auxiliar }\end{array}$ & $\begin{array}{c}\text { Procedimentos } \\
01 / 06\end{array}$ \\
\hline $\begin{array}{l}\text { Tarefas: T-2 } \\
\text { Desenvolvimento de } \\
\text { Coleções e/ou } \\
\text { Recursos } \\
\text { informacionais }\end{array}$ & $\begin{array}{l}\text { Formação de uma coleção } \\
\text { específica para atender a demanda } \\
\text { de recursos informacionais de uma } \\
\text { equipe multidisciplinar atuando em } \\
\text { Hospital Universitário }\end{array}$ & $\begin{array}{l}\text { De segunda } \\
\text { à } \\
\text { Sexta } \\
\text { Das } 8.30 \text { às } \\
17 \mathrm{~h}\end{array}$ & $\begin{array}{l}\text { Célula de } \\
\text { Documentação } \\
\text { Científica com } \\
\text { uso de } \\
\text { Computadores }\end{array}$ & $\begin{array}{c}\text { Bibliotecário e } \\
\text { Coordenador }\end{array}$ & $\begin{array}{c}\text { Procedimentos } \\
07 / 10\end{array}$ \\
\hline $\begin{array}{l}\text { Tarefas: T-3 } \\
\text { Tratamento Técnico } \\
\text { da Informação }\end{array}$ & $\begin{array}{l}\text { Classificação, catalogação e } \\
\text { preparo técnico das publicações } \\
\text { para recuperação (localização) no } \\
\text { acervo. }\end{array}$ & $\begin{array}{l}\text { De segunda } \\
\text { à } \\
\text { Sexta } \\
\text { Das } 8.30 \text { às } \\
17 \mathrm{~h}\end{array}$ & $\begin{array}{l}\text { Célula de } \\
\text { Documentação } \\
\text { Científica com } \\
\text { uso de } \\
\text { Computadores }\end{array}$ & $\begin{array}{c}\text { Bibliotecário } \\
\text { e } \\
\text { Auxiliar }\end{array}$ & $\begin{array}{c}\text { Procedimentos } \\
11 / 16\end{array}$ \\
\hline $\begin{array}{l}\text { Tarefas: T-4 } \\
\text { Circulação de } \\
\text { Material } \\
\text { Bibliográfico }\end{array}$ & $\begin{array}{l}\text { Garantir o acesso local e } \\
\text { domiciliar aos recursos } \\
\text { informacionais de acordo com o } \\
\text { Regulamento da Célula de } \\
\text { Documentação Científica. }\end{array}$ & $\begin{array}{l}\text { De segunda } \\
\text { à } \\
\text { Sexta } \\
\text { Das } 8.30 \text { às } \\
17 \mathrm{~h}\end{array}$ & $\begin{array}{l}\text { Célula de } \\
\text { Documentação } \\
\text { Científica }\end{array}$ & $\begin{array}{c}\text { Bibliotecário } \\
\text { e } \\
\text { Auxiliar }\end{array}$ & $\begin{array}{l}\text { Procedimento } \\
\qquad 17\end{array}$ \\
\hline $\begin{array}{l}\text { Tarefas: T-5 } \\
\text { Rotinas } \\
\text { Administrativas } \\
\text { inseridas na Gestão } \\
\text { da Célula de } \\
\text { Documentação } \\
\text { Científica }\end{array}$ & $\begin{array}{l}\text { Garantir a continuidade e a } \\
\text { qualidade do atendimento com } \\
\text { organização, segurança e cuidados } \\
\text { com a preservação e conservação } \\
\text { do patrimônio institucional. } \\
\text { Evitando a interrupções dos } \\
\text { serviços e a degradação dos } \\
\text { equipamentos materiais }\end{array}$ & $\begin{array}{l}\text { De segunda } \\
\text { à } \\
\text { Sexta } \\
\text { Das } 8.30 \text { às } \\
17 \mathrm{~h}\end{array}$ & $\begin{array}{l}\text { Célula de } \\
\text { Documentação } \\
\text { Científica com } \\
\text { uso de } \\
\text { Computadores }\end{array}$ & $\begin{array}{c}\text { Bibliotecário } \\
\text { e } \\
\text { Auxiliar }\end{array}$ & $\begin{array}{c}\text { Procedimentos } \\
18 / 21\end{array}$ \\
\hline $\begin{array}{l}\text { Tarefas: T-6 } \\
\text { Estudos e Pesquisas } \\
\text { e coleta de dados } \\
\text { para estatísticas }\end{array}$ & $\begin{array}{l}\text { Elaborar estudos de perfil de } \\
\text { usuários da comunidade para } \\
\text { melhor atendimento }\end{array}$ & $\begin{array}{l}\text { De segunda } \\
\text { à } \\
\text { Sexta } \\
\text { Das } 8.30 \text { às } \\
17 \mathrm{~h}\end{array}$ & $\begin{array}{l}\text { Célula de } \\
\text { Documentação } \\
\text { Científica com } \\
\text { uso de } \\
\text { Computadores }\end{array}$ & $\begin{array}{c}\text { Bibliotecário } \\
\text { e } \\
\text { Auxiliar }\end{array}$ & $\begin{array}{c}\text { Procedimentos } \\
22 / 23\end{array}$ \\
\hline $\begin{array}{l}\text { Tarefas: } \mathbf{T - 7} \\
\text { Orientação de } \\
\text { Estagiários }\end{array}$ & $\begin{array}{l}\text { Contribuir na formação de } \\
\text { profissionais da informação, } \\
\text { através da vivência prática, para } \\
\text { que haja um compartilhamento de } \\
\text { informações e experiências } \\
\end{array}$ & $\begin{array}{l}01 \text { vaga por } \\
\text { semestre }\end{array}$ & $\begin{array}{l}\text { Célula de } \\
\text { Documentação } \\
\text { Científica }\end{array}$ & Bibliotecário & $\begin{array}{l}\text { Procedimento } \\
24\end{array}$ \\
\hline
\end{tabular}

Fonte: Célula de Documentação Científica - 2006

\section{Observa-se que a Equipe de Informação da Célula de Documentação Científica possui} sete grandes tarefas que norteiam e garantem a gestão de processos. Para exemplificação, será detalhada abaixo a Tarefa (T-1) da gestão de processos por estar diretamente vinculada ao exercício da competência informacional, como segue: 
“Realizar pesquisa de documentos em bases de dados especializadas; possibilitar a localização e obtenção de documentos; orientar o usuário nas buscas, na elaboração e apresentação de trabalhos técnicos científicos e disseminar seletivamente as informações de interesse potencial dos usuários.”

A Tarefa (T-1) é composta por seis procedimentos e o detalhamento de cada atividade é:

1) Pesquisa bibliográfica ou levantamento bibliográfico: esta atividade tem como objetivo atender a uma questão de referência elaborada pelo pesquisador, ou seja, um pedido por informação ou auxílio para localizá-la. Pode ser uma busca de referências bibliográficas sobre assuntos específicos necessário ao desenvolvimento de uma pesquisa acadêmica, ou para outros fins, como por exemplo: elaboração de protocolos de atendimentos; redação de livros; elaboração de consensos, elaboração de projetos de gestão; informações para tomada de decisão clínica etc.

2) Solicitação de cópias de artigos em textos completos: é um processo de finalização de levantamentos já realizados pelo pesquisador, no qual é possibilitado ao pesquisador o acesso ao texto completo de artigos de periódicos, seja por meio de cópias reprográficas quando tratar-se de artigo referente ao acervo impresso de periódicos científicos da instituição; seja por download de periódicos online ou ainda utilizando o serviço de Comutação Bibliográfica. Este procedimento é uma conseqüência dos procedimentos: 1) Pesquisa bibliográfica ou levantamento bibliográfico e 4) Instrução de pesquisas.

3) Obtenção de documentos (livros, teses etc): objetiva o acesso aos documentos, seja através de Empréstimos, Comutação ou Download em Bibliotecas Digitais, Arquivos, Repositórios, etc. Procedimento também complementar aos procedimentos um e quatro.

4) Instrução de pesquisas: este procedimento tem como finalidade orientar os usuários sobre os recursos informacionais e as fontes de informações disponíveis na instituição e também outras fontes de informações da Área de Ciências da Saúde e seus acessos; orientar as buscas em bases de dados especializadas e os percursos para a Obtenção de documentos (procedimento 3); Realizar busca de critérios de avaliação de impacto ou qualidade, por 
exemplo: Fator de Impacto e índices de Citação (ISI Web of Knowledge, Journal Citation Reports, Scopus, Scielo etc.); Conceito Qualis (CAPES) etc.

5) Normalização de trabalhos técnicos - científicos: este procedimento tem como objetivo orientar os usuários na elaboração e apresentação de trabalhos de acordo com as normas técnicas utilizadas na instituição; Orientar os pesquisadores sobre processo de produção e comunicação de publicações científicas como: normas de submissão de artigos para publicações; forma de obtenção de registros de publicações (ISBN, ISSN), elaboração de fichas catalográficas emitidas na fonte etc.

6) Disseminação seletiva de informação (DSI): atividade cujo objetivo é disponibilizar e divulgar informações e acessos de interesse potencial dos usuários, através de atendimento personalizado, o que inclui a divulgação de novas aquisições; divulgação de senhas; divulgação de bases de dados; divulgação de artigos e textos etc.

\section{Conclusão}

A existência de uma Unidade Informacional inserida em Hospital Universitário propicia o rápido acesso a informação e evidencia a demanda deste serviço na área hospitalar.

A área da saúde passa por uma explosão informacional, não bastando apenas recorrer aos levantamentos bibliográficos tradicionais. Novas técnicas e novas teorias surgem para auxiliar na escolha do melhor recurso informacional.

O profissional da informação inserido neste contexto tem a sua disposição diversos recursos informacionais que podem ser utilizados para acesso e recuperação da informação confiável. Pode-se dizer que as questões fundamentais que envolvem pesquisas bibliográficas na área da saúde já foram consolidadas, fato este que pode ser comprovado quando observadas as formas de organização dos periódicos especializados e a gerência das bases de dados, situações ainda de difícil solução em outras áreas do conhecimento. 
Fazer uso da Competência Informacional como uma ferramenta na tarefa de capacitar o pesquisador, profissional da saúde, aproveitando melhor os recursos informacionais disponíveis na instituição é uma escolha acertada do profissional da informação.

Nota-se que essa nova conduta vai ao encontro da Competência Informacional/ Information Literacy, pois apresenta na prática o que a literatura define e estabelece. A Competência Informacional contribui muito com o profissional da informação como sendo uma ferramenta para capacitação do pesquisador, e por outro lado, permite ao pesquisador autoconfiança por meio da habilidade adquirida.

A atuação do profissional da informação na área da saúde deixa de ser vista e vivenciada pelos pesquisadores, profissionais da saúde, como um suporte, fortalecendo uma nova conduta, a de orientador, que está mais direcionada a educação e capacitação do pesquisador, contribuindo para o seu desenvolvimento desde a seleção das bases de dados até a recuperação da informação confiável.

Espera-se que a divulgação deste relato de experiência possa contribuir para que outras unidades de informação possam organizar seus serviços e atender com qualidade suas demandas, principalmente da área da saúde, campo fértil de pesquisas que está sempre revendo e melhorando suas técnicas e buscando novos conhecimentos.

\section{REFERÊNCIAS}

ASSOCIATION OF COLLEGE \& RESEARCH LIBRARIES. Literacy Competency Standards for Higher Education. 2000. Disponível em: < http://www.ala.org/ala/acrl/acrlstandards/informationliteracycompetency.htm>. Acesso em: 09 maio 2007.

BLATT, I. M. Serviço de informação nas unidades hospitalares administradas pela Secretaria de Estado da Saúde de Santa Catarina. Revista ACB, Florianópolis, v.6, n. 1, p.97-110, 2001.

BUENO, S. B.; BLATTMANN, U. Fontes de informação on-line no contexto da área de Ciências da Saúde. Revista Digital de Biblioteconomia e Ciência da Informação, Campinas, v.2, n.2, p. 1-17, 2005.

(C) Revista Digital de Biblioteconomia e Ciência da Informação,Campinas, , v.7, n. 1, p. 180-189, jul./dez. 2009- ISSN: 1678-765X. 
CAVALCANTE, L. E. Políticas de formação para a competência informacional: o papel das universidades. Revista Brasileira de Biblioteconomia e Documentação: Nova Série, São Paulo, v.2, n.2, p.47-62, 2006.

DUDZIAK, E. A. Information literacy: princípios, filosofia e prática. Ciência da Informação, Brasília, v.32, n. 1, p. 23-35, 2003.

EVANGELISTA, R.; OLIVEIRA, V.F.F.; PEREIRA, S.L.; PETINARI, V.S. Competência informacional e medicina baseada em evidências. Transinformação, Campinas, v. 20, n. 1, p. 73-81, 2008.

FARIA, S.; OLIVEIRA, V.F.F.; FORNER, L; D’ASTUTO, F. Competências do profissional da informação: uma reflexão a partir da Classificação Brasileira de Ocupações. Ciência da Informação, Brasília, v. 34, n.2, p. 26-33, 2005.

LE COADIC, Y.F. A Ciência da Informação. 2 ed. Brasília: Briquet de Lemos, 2004.

PINTO, R. R. O profissional da informação em Ciências da Saúde: subsídios para o desenvolvimento de cursos de capacitação no Brasil. 2005. p. Dissertação (Mestrado Profissional) - Escola Paulista de Medicina, São Paulo, 2005.

SILVA, F.C.C. A atuação do bibliotecário médico e sua interação com os profissionais da saúde para busca e seleção de informação especializada. Revista Digital de Biblioteconomia e Ciência da Informação, Campinas, v.3, n.1, p. 131-151, 2005.

UNIVERSIDADE ESTADUAL DE CAMPINAS. Centro de Atenção Integral à Saúde da Mulher. Célula de Documentação Científica. Relatório de gestão de processos. Campinas, 2006 (Trabalho não publicado). 


\section{Valdinéa Sonia Petinari}

Graduada em Tecnologia em Processamento de Dados - UNISAL e Ciência da Informação com Habilitação em Biblioteconomia - PUC-Campinas. Especialista em Gerência de Sistemas e Serviços de Informação. Responsável pela Central de Referência em Equipamentos Biomédicos do CEB/UNICAMP. val@ceb.unicamp.br

\section{Vanda de Fátima Fulgêncio de Oliveira}

Graduada em Ciências Sociais e Biblioteconomia - PUC - Campinas. Bibliotecária do Centro de Atenção Integral à Saúde da Mulher (CAISM) da UNICAMP. vanda@unicamp.br

\section{Rosana Evangelista}

Mestre em Biblioteconomia - PUC-Campinas. Bibliotecária da Faculdade de Ciências Médicas da UNICAMP. rosanae@fcm.unicamp.br

\section{Sandra Lúcia Pereira}

Mestre em Biblioteconomia - PUC-Campinas. Bibliotecária da Faculdade de Ciências Médicas da UNICAMP. sandralu@fcm.unicamp.br

Recebido em: 08/02/2008

Aceito para publicação em: jan/2009 